\title{
NOTES AND LETTERS
}

GREAT GRAY OWL GRAY SQUIRREL ENCOUNTER

About noon on 29 February 1996, Douglas spotted a Great Gray Owl flapping around our back garden, trying to grab a Gray Squirrel off one of the trees by the rear chain-link fence. The squirrel escaped through the fence and hid under a couple of scrub fir trees. Blundering through the lower branches, the owl attempted to grab the squirrel, which again escaped. This time it nipped across the rear neighbour's lot to a steel wheelbarrow propped up against a tree. The squirrel then hunkered down between the wheelbarrow and the trunk of the tree, while the owl perched on top of the wheelbarrow's handle. After 45 minutes and with the squirrel still in hiding, the owl flew 10 feet away to perch on a stump. At this point a couple of Blue Jays started to harass the owl, but it just ignored them. After a further half hour or so, the squirrel headed off towards the neighbour's side gate. At once, the owl gave chase and after a lot of flapping it seized the squirrel, then dragged its heavy burden back under the fir tree by our fence. There it sat on the squirrel, killed it and began to feed on it.
We were amazed next morning (1 March) to find the owl still in position on top of his meal. Throughout the day, despite visits by numerous friends and neighbours who came by to see our unusual visitor, the owl continued to feed on the squirrel. During these proceedings, other Gray Squirrels kept coming around to berate the owl, when they were not chasing each other. Not very bright squirrels! By 1800 hours, the owl, seemingly unconcerned about all the interest it had stirred up in this peaceful neighbourhood, finally took off.

The next morning, while eating breakfast, Doug happened to glance towards our neighbour's crab apple tree, and there, on a stump, sat the owl. Before we could take a picture, it flew away. We saw it fly over twice more before it disappeared for good. Later, a number of birders came by, hoping to see the owl, but the only trace was the picked-over carcass of the squirrel. Since Great Gray Owls rarely occur in Winnipeg, and seldom prey on Gray Squirrels, this was our highlight of the year.

- ALINE AND DOUGLAS LUDLOW, 77 Sandra Bay, Winnipeg, MB. R3T 0J9

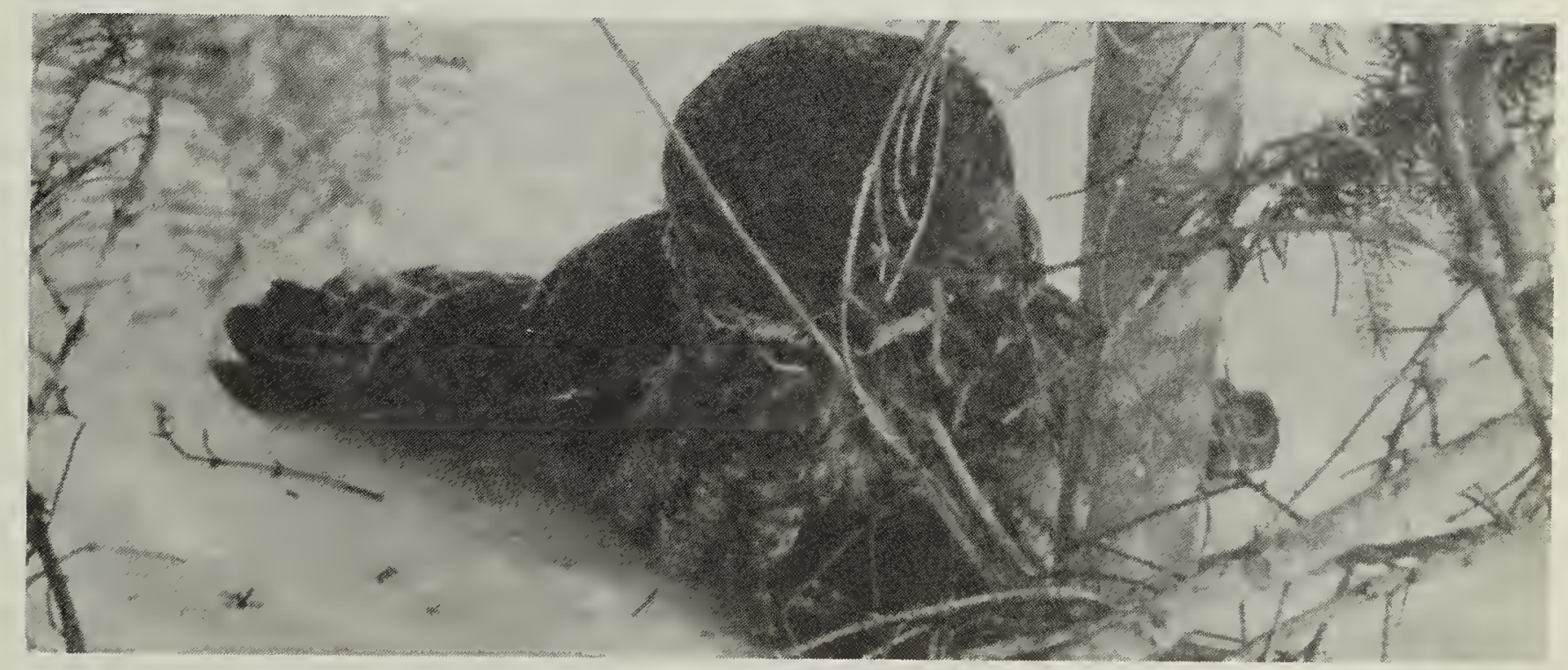

